\title{
ASPECTOS BIOÉTICOS DA CIRURGIA DE REDESIGNAÇÃO SEXUAL SOB A ÓTICA DA REALIZAÇÃO DO DIREITO FUNDAMENTAL À SAÚDE
}

\author{
MARIA CLAUDIA CRESPO BRAUNER ${ }^{1}$ \\ LAÍSE GRAFF ${ }^{2}$
}

\begin{abstract}
RESUMO: Este estudo introduz alguns aspectos bioéticos da cirurgia de redesignação sexual destinada ao tratamento às pessoas transexuais, sob a ótica da concretização do direito fundamental à saúde. O sofrimento psíquico vivenciado pelos transexuais decorre especialmente do conflito entre suas características anatômicas e sua identidade sexual. Considerando a transexualidade como um transtorno capaz de gerar significativo sofrimento, cabe questionar sobre as formas e os limites da intervenção médica para seu tratamento, em especial a cirurgia de reatribuição sexual, tomando como base princípios e conceitos oferecidos pela Bioética. Estando reconhecida como doença diagnosticável e passível de tratamento, trata-se sobre a disponibilização de tratamento aos transexuais como forma de realização do direito à saúde.

PALAVRAS-CHAVE: Direito à Saúde; Bioética; Transexualidade.

ABSTRACT: This study introduces some of the bioethical aspects on sexual redesignation surgery focused on the treatment to transexual people, under an optics from the accomplishment of fundamental right to health. The psychic suffering lived by the transexual individuals can accrue mainly in the conflict between their anatomical characteristics and their sexual identity. Considering transexuality as a disorder able to develop a significant amount of suffering, it is worth to question the forms and the limits of medical intervention for their treatment, paying special attention to the sexual reassignment surgery, using as a basis the principles and the concepts offered by the Bioethics. Being acknowledged as a diagnosed disease and liable for treatment, it is about the availability of treatment to the transexual individuals as a manner to accomplish the right to health. KEYWORDS: Right to Health; Bioethics; Transexuality.
\end{abstract}

Artigo recebido em 08.08.2011. Pareceres emitidos em 11.11.2011 e 14.02.2012.

Artigo aceito para publicação em 12.03.2012.

${ }^{1}$ Doutora em Direito pela Université de Rennes I - França; Pós-Doutorado na Université de Montréal1 - Canadá. Professora Adjunta na Graduação e Mestrado e Pesquisadora na Universidade de Caxias do sul/RS - UCS e Professora Adjunta da Faculdade de Direito da Universidade Federal do Rio Grande/RS - FURG. Pesquisadora Produtividade do CNPq. mccbraun@ucs.br

${ }^{2}$ Mestranda em Direito Ambiental pela Universidade de Caxias do Sul/RS - UCS. Bolsista CAPES. Pós-Graduada em Direito Penal pela mesma universidade. Analista Judiciária da Justiça Federal de $1^{\circ}$ Grau do Rio Grande do Sul. laisegraff@hotmail.com 
SUMÁRIO: Introdução; 10 Transexualismo como Sofrimento Psíquico; 2 Aspectos Bioéticos da Cirurgia de Transgenitalização; 3 O Tratamento do Transtorno de Identidade de Gênero e o Direito Fundamental à Saúde; Considerações Finais; Referências Bibliográficas.

SUMMARY: Introduction; 1 Transexualism as a Psychic Suffering; 2 Bioethical Aspects of the Transgenitalization Surgery; 3 The Treatment for Gender Identity Disorder and the Fundamental Right to Health; Final Considerations; Bibliographical References.

\section{INTRODUÇÃO}

O reconhecimento do equilíbrio entre meio ambiente, indivíduo e sociedade como fator essencial para o bem-estar do ser humano tem acompanhado a história da humanidade, com variados graus de importância. No despertar da filosofia ocidental, vários pensadores exaltavam a necessidade da convivência harmônica do homem com a natureza para sua saúde e sobrevivência. Essa ideia foi defendida sob diferentes perspectivas pelos filósofos gregos da Antiguidade, como bem exemplifica a afirmação de Platão de que "o estado de equilíbrio interno do homem, e dele com a organização social e a natureza, é sinônimo de saúde". ${ }^{3}$

Passados mais de dois mil anos desde o apogeu da filosofia grega, a interação entre sociedade, meio ambiente e saúde hoje recobra importância, ganhando papel de destaque na concretização de direitos humanos o bem-estar de cada indivíduo e sua integração social.

Nesse âmbito, o lugar ocupado por cada pessoa na estrutura social e sua interação com o coletivo desempenham fator importante no desenvolvimento humano - seja impulsionando, seja restringindo as possibilidades individuais. Neste contexto, o sexo biológico, os papéis e as identidades de gênero são fatores especialmente determinantes para as respostas que cada indivíduo estará sujeito a receber do corpo social, tais como aceitação ou hostilidade, tolerância ou preconceito, limitações etc.

Embora atualmente a sociedade ainda permaneça predominantemente regida segundo um padrão sexual binário - homem ou mulher, masculino ou feminino -, cada vez mais surgem indivíduos e grupos reivindicando e promovendo quebras desse paradigma, "em uma era de multiplicação de sexualidades, reinvenção dos gêneros e sua definitiva desvinculação do sexo biológico." ${ }^{4}$

Dentre os diversos representantes dessas manifestações que destoam do padrão social - travestis, homossexuais, bissexuais etc. -, encontram-se também os transexuais, para quem o sexo biológico não corresponde à sua identidade de gênero. Segundo a Associação Psiquiátrica Americana, a

${ }^{3}$ PLATÃO. A República. São Paulo: Martins Fontes, 2004, p. 38.

${ }^{4}$ MISKOLCI, Richard. Ascensão e Queda. In: PINTO, Graziela Costa (Org.). Uma Questão de Gênero. São Paulo: Duetto Editorial, 2008, p. 30. 
transexualidade pode ser associada ao transtorno de identidade de gênero, conceituado como uma forte e persistente identificação com o gênero oposto e um desconforto persistente e sensação de inadequação no papel de gênero deste sexo. ${ }^{5}$

Com o avanço das pesquisas no âmbito da Psicologia, associado às inovações das técnicas médicas que permitiram a realização de cirurgias de redesignação sexual - popularmente conhecidas como cirurgias de "troca" ou "mudança" de sexo -, iniciou-se o debate no campo da Bioética sobre a legitimidade dessa intervenção, tendo como base sua real função terapêutica e os limites da liberdade de dispor sobre o próprio corpo. No Direito, a discussão centrou-se sobre sua licitude, em face dos crimes contra a pessoa, bem como sobre as consequências jurídicas, especialmente no âmbito dos direitos da personalidade e do direito de família.

Em razão da amplitude do tema, a proposta do presente estudo é analisar certos aspectos bioéticos da cirurgia de redesignação sexual destinada ao tratamento às pessoas transexuais, sob a ótica da concretização do direito fundamental à saúde. Será conferida ênfase à necessidade de acesso ao tratamento no plano psicológico, hormonal, cirúrgico e de readequação social.

\section{TRANSEXUALISMO COMO SOFRIMENTO PSÍQUICO}

Para o entendimento do transexualismo - também denominado como Síndrome de Benjamim ou Síndrome da Disforia de gênero - como transtorno de identidade de gênero, é necessário inicialmente traçar as diferenças entre os conceitos de sexo e de gênero.

Enquanto o sexo designa os caracteres biológicos e anatômicos que diferenciam o homem da mulher, o conceito de gênero é entendido como a construção social do masculino e do feminino, considerando as características e comportamentos esperados dos homens e das mulheres, pela sociedade e pela cultura em que estão inseridos, em dado período histórico. João Batista Pedrosa destaca outros importantes desdobramentos deste conceito:

Identidade de gênero é a convicção íntima de uma pessoa de ser do gênero masculino (homem) ou feminino (mulher), diferentemente do papel de gênero, representado pelos padrões de comportamentos definidos pela prática cultural em que as pessoas vivem papéis esterotipadamente masculinos e femininos. ${ }^{6}$

Assim, a identidade de gênero refere-se ao sentimento e à noção individual de pertencer a um dos gêneros, masculino ou feminino. O transexual, portanto, possui uma identificação com o gênero oposto ao

${ }^{5}$ ASSOCIAÇÃO AMERICANA DE PSIQUIATRIA. Manual Diagnóstico e Estatístico de Transtornos Mentais - DSM-IV. Trad. Cláudia Dornelles. 4. ed., Porto Alegre: Artmed, 2002, p. 547.

${ }^{6}$ PEDROSA, João Batista. Característica Comportamental e Gênero. In: VIEIRA, Tereza Rodrigues; PAIVA, Luiz Airton Saavedra de. (Org). Identidade Sexual e Transexualidade. São Paulo: Roca, 2009, p. 58. 
seu sexo biológico. Como referem Marlene Inácio e Elisa del Rosario Ugarte Verduguez, o transexualismo é um transtorno de identidade sexual, no qual existe forte e persistente identificação com o sexo oposto e um descontentamento com a genitália e com os caracteres sexuais secundários, bem como com as atribuições sociais pertinentes ao sexo biológico."

É importante destacar que a problemática do transexual não se confunde com a situação dos intersexuais, bissexuais, homossexuais e travestis.

O homossexual sente atração sexual por pessoas do mesmo sexo, estando essa preferência relacionada com a orientação afetivo-sexual. Segundo Elio Sgreccia, na homossexualidade não se sentem os aspectos físicos do sexo num sentido ambíguo e conflitante: são usados em vista da satisfação erótica posta num indivíduo do mesmo sexo. O homossexual não deseja mudar de sexo, mas simplesmente ter relações sexuais com indivíduos do mesmo sexo. ${ }^{8}$

Da mesma forma, os indivíduos bissexuais sentem atração sexual por homens e mulheres, não manifestando conflito psíquico com suas características físicas ou com seu papel de gênero. Os travestis, de outra parte, não apresentam desconforto com o sexo físico; usam roupas típicas do sexo oposto e podem até adquirir definitivamente outros caracteres secundários deste (implante de mamas, aplicação de hormônios etc.), com o objetivo de obter estimulação sexual. ${ }^{9}$ Vários autores destacam que 0 travesti não é necessariamente um homossexual. ${ }^{10}$

Já os intersexuais são os vulgarmente designados como "hermafroditas", porque possuem características genéticas ou cromossômicas de ambos os sexos. Podem apresentar genitália ambígua, envolvendo "mistura, em vários graus, de características de cada sexo, incluindo forma física, órgãos reprodutivos e comportamento sexual"11. Segundo Dorina Quaglia, são raros os casos de hermafroditismo verdadeiro, que consiste na coexistência de tecido ovariano e testicular no mesmo indivíduo ${ }^{12}$. Enfim, são diversas

\footnotetext{
7 INÁCIO, Marlene; VERDUGUEZ, Elisa del Rosario Ugarte. Experiência em Avaliação Psicológica da Transexualidade no Hospital das Clínicas da Faculdade de Medicina da Universidade de São Paulo. In: VIEIRA, Tereza Rodrigues; PAIVA, Luiz Airton Saavedra de. (Org). Identidade Sexual e Transexualidade. São Paulo: Roca, 2009, p. 64.

SGRECCIA, Elio. Manual de Bioética. I - Fundamentos e Ética Biomédica. Trad. Orlando Soares Moreira. 2. ed., São Paulo: Edições Loyola, 2007, p. 504.

9 PEDROSA, João Batista. Característica Comportamental e Gênero. In: VIEIRA, Tereza Rodrigues; PAIVA, Luiz Airton Saavedra de. (Org). Identidade Sexual e Transexualidade. São Paulo: Roca, 2009, p. 60.

10 QUAGLIA, Dorina. Intersexualidade. In: VIEIRA, Tereza Rodrigues; PAIVA, Luiz Airton Saavedra de. (Org). Identidade Sexual e Transexualidade. São Paulo: Roca, 2009, p. 46.

${ }_{11}$ RAMSEY, Gerald. Transexuais: perguntas e respostas. Trad. Rafael Azize. São Paulo: Summus, 1998, p. 43.

${ }_{12}$ QUAGLIA, Dorina. Intersexualidade. In: VIEIRA, Tereza Rodrigues; PAIVA, Luiz Airton Saavedra de. (Org). Identidade Sexual e Transexualidade. São Paulo: Roca, 2009, p. 39.
} 
as síndromes e anomalias caracterizadoras de intersexualidade, mas o fundamental é que nesses casos a origem do distúrbio é sempre de ordem biológica.

Para finalizar essas distinções preliminares, sublinha-se que a etiologia da transexualidade não encontra consenso entre os autores, existindo teorias organicistas - segundo as quais o transtorno teria causas orgânicas, tais como as hormonais e genéticas -, teorias psicológicas, que entendem que a causa seria basicamente psíquica, e teorias mistas, que conjecturam sobre a união das teorias orgânicas e psicológicas. ${ }^{13}$

Tratando sobre a complexidade da formação psicossexualidade, Marlene Inácio e Elisa del Rosario Ugarte Verduguez apresentam a seguinte síntese, indicando os motivos das dificuldades de identificar as causas do transtorno, pois o desenvolvimento da psicossexualidade é influenciado por múltiplos fatores, como os genéticos, de estrutura cerebral, exposição aos hormônios durante a gestação, influências socioculturais, dinâmica familiar e os desejos conscientes e inconscientes parentais. ${ }^{14}$

Independentemente das origens do conflito, o transexual apresenta importante sofrimento psíquico, ocasionado pelo seu inconformismo entre as determinantes biológicas de seu sexo (físico) e sua identificação com o gênero oposto, a dinâmica psíquica dos transexuais, se desdobra da seguinte maneira: apresentam um conflito entre realidade anatômica e identidade sexual, cujo sentimento de identidade sexual, que não concorda com a anatomia, manifesta uma exigência compulsiva, imperativa e inflexível de adequação de sexo. A convicção de incompatibilidade entre aquilo que são anatomicamente e aquilo que sentem ser, pode levar esses indivíduos à autoemasculação e até mesmo ao suicídio. O sofrimento psíquico do transexual está entre, de um lado, a anatomia do sujeito e seu 'sexo psicológico' e, de outro, esse mesmo 'sexo psicológico' e sua

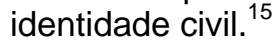

Além da sensação permanente de incongruência física experimentada pelo transexual, vários autores referem que é comum a presença de um intenso sentimento de inadequação social, que o acompanha ao longo da vida. Dos relatos de pacientes, encontrados na bibliografia consultada, chama a atenção o fato de muitos deles referirem sérias dificuldades de relacionamento nos diversos âmbitos sociais - família, trabalho, amizades, escola, etc..

\footnotetext{
${ }^{13}$ ALMEIDA, Sérgio de. In: VIEIRA, Tereza Rodrigues; PAIVA, Luiz Airton Saavedra de. (Org). Identidade Sexual e Transexualidade. São Paulo: Roca, 2009, p. 51.

14 INÁCIO, Marlene; VERDUGUEZ, Elisa del Rosario Ugarte. Experiência em Avaliação Psicológica da Transexualidade no Hospital das Clínicas da Faculdade de Medicina da Universidade de São Paulo. In: VIEIRA, Tereza Rodrigues; PAIVA, Luiz Airton Saavedra de. (Org). Identidade Sexual e Transexualidade. São Paulo: Roca, 2009, p. 64.

${ }^{15}$ Id. Ibid., p. 64.
} 
Em crianças mais velhas, é comum o isolamento e o sofrimento pelo fracasso em desenvolver relacionamentos, sendo que "algumas podem recusar-se a comparecer à escola em razão de zombaria ou pressões no sentido de vestirem-se de acordo com o estereótipo de seu sexo."16

São também frequentes os sintomas de ansiedade e depressão, estando ainda presente a possibilidade de autoagressão, automutilação e suicídio, ou ainda de um comprometimento no funcionamento social e ocupacional, em consequência do desejo de desempenhar o papel do gênero oposto. A depressão é um problema comum, especialmente se o indivíduo sente falta de esperanças quanto a obter uma mudança de sexo com cirurgia ou hormônios. Os homens podem castrar a si mesmos, não em uma tentativa de suicídio, mas como um modo de forçar um cirurgião a tratar de seu problema. ${ }^{17}$

Gerald Ramsey, psicólogo dedicado ao acompanhamento do processo terapêutico e cirúrgico de redesignação sexual, enfatiza que o processo transexual - a jornada que começa com uma terapia e vestir-se como o outro sexo, passa por tratamento hormonal e termina com cirurgia não é um capricho passageiro. É a busca consistente de integração física, emocional, social, espiritual e sexual, conquistada a enormes penas pessoais. ${ }^{18}$

Miriam Ventura igualmente destaca a constante busca por adequação pessoal dos transexuais, este antagonismo vivenciado entre sexo biológico e gênero, que faz com que a pessoa transexual busque de forma persistente adequar seu corpo ao sexo que crê possuir. Esta 'mudança de sexo' é realizada através de extensas intervenções cirúrgicas, com a ablação de órgãos - pênis, mama, útero, ovários - e reconstrução de uma nova genitália - cirurgia de transgenitalização -, e tratamento hormonal para transformação dos caracteres sexuais secundários. ${ }^{19}$

Deste modo, a partir do reconhecimento da transexualidade como um transtorno capaz de gerar significativo sofrimento psíquico - e não um pensamento eventual ou uma escolha autônoma do indivíduo -, cabe perquirir sobre as formas e os limites de intervenção médica em seu tratamento a partir das reflexões da Bioética.

${ }^{16}$ ASSOCIAÇÃO AMERICANA DE PSIQUIATRIA. Manual Diagnóstico e Estatístico de Transtornos Mentais - DSM-IV. Trad. Cláudia Dornelles. 4. ed., Porto Alegre: Artmed, 2002, p. 549.

17 KAPLAN, Harold I.; SADOCK, Benjamin J.; GREBB, Jack A. Compêndio de Psiquiatria: ciências do comportamento e psiquiatria clínica. Trad. Dayse Batista. 7. ed., Porto Alegre: Artes Médicas, 1997, p. 644.

${ }_{18}$ RAMSEY, Gerald. Transexuais: perguntas e respostas. Trad. Rafael Azize. São Paulo: Summus, 1998, p. 32.

${ }^{19}$ VENTURA, Miriam. Transexualidade: algumas reflexões jurídicas sobre a autonomia corporal e autodeterminação da identidade sexual. In: RIOS, Roger Raupp. (Org). Em Defesa dos Direitos Sexuais. Porto Alegre: Livraria do Advogado Editora, 2007, p. 142. 
2 ASPECTOS BIOÉTICOS DA CIRURGIA DE TRANSGENITALIZAÇÃO

Considerando a possibilidade atualmente oferecida pela medicina, de readequar a corpo das pessoas no intuito de tratar o transtorno de identidade de gênero, muitos autores defendem o uso deste recurso visando a busca de uma melhoria de qualidade de vida. Como argumenta Gilles Lipovetsky, "a natureza não tem caráter sagrado: corrigir as 'anomalias' que são fonte de sofrimento não constitui um ato diabólico, é um progresso humanista." 20 O autor defende que, dentro do que denomina de "era do pós-dever", predomine o direito de cada indivíduo dispor de si próprio, em contraposição aos deveres incondicionais, representando uma vitória do 'sexo psicológico' sobre o 'sexo morfológico'. Pondera, contudo, que seu entendimento não enseja 'barbárie individualista', mas sim uma escalada rumo a valores mais abertos e tolerantes, "onde os princípios de imutabilidade do registro civil e de respeito pelo corpo humano já não são concebidos de forma absolutista." ${ }^{21}$

Assim, abre-se o debate sobre os limites do tratamento do transexual, cujo corpo ele renega, entendendo que não corresponde ao sexo que sente como seu.

A cirurgia de transgenitalização também é denominada de cirurgia de adequação sexual, de redesignação sexual ou de reatribuição sexual. Segundo Gerald Ramsey, a redesignação sexual cirúrgica genital refere-se à cirurgia da genitália e/ou mamas realizada com o propósito de alterar a morfologia de modo a aproximar a aparência física do outro sexo genético, em pessoas diagnosticadas como tendo distúrbio de identidade de gênero. Procedimentos cirúrgicos tais como mastectomia, mamoplastia redutora, mamoplastia de aumento, castração, orquidectomia, penectomia, vaginoplastia, histerectomia, salpingectomia, vaginectomia, uforectomia e faloplastia, na ausência de algum defeito genésico diagnosticável ou outra patologia clinicamente definida, exceto a disforia de gênero, estão incluídos na categoria classificada como cirurgia de redesignação sexual. ${ }^{22}$

Quanto aos aspectos éticos, a indicação da cirurgia ainda é um tema bastante controvertido entre os profissionais da área médica, especialmente quanto à sua real possibilidade de contribuir para a melhoria da qualidade de vida dos transexuais. Por se tratar de uma intervenção definitiva, a decisão de sua realização deve estar cercada de diversos cuidados. Assim, muito embora transexuais adolescentes e adultos frequentemente solicitem procedimentos cirúrgicos para alterarem sua aparência física ${ }^{23}-$, dado que

20 LYPOVETSKI, Gilles. O Crepúsculo do Dever. A Ética Indolor dos Novos Tempos Democráticos. Trad. Fátima Gaspar e Carlos Gaspar. Lisboa: Dom Quixote, 2004, p. 110.

${ }^{21}$ LYPOVETSKI, Gilles. O Crepúsculo do Dever. A Ética Indolor dos Novos Tempos Democráticos. Trad. Fátima Gaspar e Carlos Gaspar. Lisboa: Dom Quixote, 2004, p. 110.

22 RAMSEY, Gerald. Transexuais: perguntas e respostas. Trad. Rafael Azize. São Paulo: Summus, 1998, p. 175.

${ }^{23}$ KAPLAN, Harold I.; SADOCK, Benjamin J.; GREBB, Jack A. Compêndio de Psiquiatria: ciências 
possuem a preocupação persistente em livrar-se de suas características sexuais primárias e secundárias e adquirir as do sexo oposto -, a cirurgia de readequação sexual não deve ser realizada mediante o mero requerimento do paciente, como comumente ocorre no caso das cirurgias plásticas, por exemplo.

Trata-se assim, de pensar sobre os limites dos atos de disposição do próprio corpo. Segundo o art. 13 do Código Civil "salvo por exigência médica, é defeso o ato de disposição do próprio corpo, quando importar diminuição permanente da integridade física, ou contrariar os bons costumes". Contudo, é possível afirmar que no contexto do transtorno de identidade de gênero, a realização da cirurgia, embora extremamente interventiva e de caráter definitivo, ganha contornos de verdadeira intervenção terapêutica.

Especialmente pelo fato de o transexual apresentar compulsão no sentido de realizar a cirurgia, diante de sua preocupação persistente em livrar-se de suas características sexuais, ressalta-se a necessidade de ponderação e discernimento por parte do corpo médico. Assim, a fim de evitar decisões equivocadas e o posterior arrependimento do paciente, os especialistas foram desenvolvendo diversos protocolos e requisitos para o atendimento de transexuais, com ênfase na estipulação de critérios cuidadosos precedentes à cirurgia. Dentre as etapas pré-cirúrgicas exigidas, cita-se a ministração de hormônios (que irão estimular o aparecimento de caracteres secundários do sexo desejado), a tentativa de viver como o sexo oposto, vestindo-se e comportando-se como tal (também chamado de teste da vida real) ${ }^{24}$, além de uma criteriosa avaliação do candidato à cirurgia por uma equipe transdisciplinar.

Para Gerald Ramsey, uma equipe cirúrgica séria não pode operar todas as pessoas diagnosticadas como transexuais, destacando que o diagnóstico é apenas o primeiro passo do processo. O autor entende que uma operação não deve ser realizada a menos que existam motivos consistentes para acreditar que o transexual terá uma melhora emocional significativa, e que eventuais sintomas psicológicos remanescentes poderão ser tratados de forma mais eficaz após a cirurgia. Conclui Ramsey que, "devido à importância dessa decisão, creio que tais determinações são primordialmente da alçada de uma equipe de clínicos, médicos e cirurgiões experientes, e não de aventureiros solitários." ${ }^{25}$

Tais cuidados e requisitos, estipulados pelo próprio meio médico e embasados nas experiências realizadas ao longo das últimas décadas,

do comportamento e psiquiatria clínica. Trad. Dayse Batista. 7. ed., Porto Alegre: Artes Médicas, 1997, p. 643.

${ }^{24}$ KAPLAN, Harold I.; SADOCK, Benjamin J.; GREBB, Jack A. Compêndio de Psiquiatria: ciências do comportamento e psiquiatria clínica. Trad. Dayse Batista. 7. ed., Porto Alegre: Artes Médicas, 1997, p. 646.

${ }^{25}$ RAMSEY, Gerald. Transexuais: perguntas e respostas. Trad. Rafael Azize. São Paulo: Summus, 1998, p. 46. 
demonstram a preocupação com o princípio bioético da beneficência, segundo o qual as ações na área da saúde devem estar voltadas para a vida e o bem do ser humano, englobando "não apenas a atitude de impedir e remover danos e prover benefícios, mas também equilibrar os possíveis bens e os possíveis danos de uma ação." ${ }^{26}$

Além disso, também há respeito ao princípio bioético da autonomia, identificado com o respeito à vontade da pessoa, aos seus valores e crenças, uma vez que o paciente deve ser suficientemente esclarecido sobre os riscos, a irreversibilidade e as consequências da intervenção a que pretende submeter-se, podendo decidir livremente sobre sua realização.

José Roque Junges destaca que o princípio da autonomia e da beneficência não são excludentes, mas sim, complementares, aplicando-se ao caso da cirurgia essa ideia de equilíbrio pois a autonomia não é uma alternativa para a beneficência. Devem ser complementares. Por um lado, a autonomia está a serviço da beneficência, para que esta não seja redutiva e desrespeitosa. Por outro, a beneficência está a serviço da autonomia, para que esta possa chegar a um consentimento informado e competente. ${ }^{27}$

No Brasil, o Conselho Federal de Medicina - CFM, por meio da Resolução $n^{0}$ 1.482/97, autorizou, inicialmente a título experimental, a realização de cirurgia de transgenitalização do tipo neocolpovulvoplastia, neofaloplastia e procedimentos complementares sobre gônadas e caracteres sexuais secundários como tratamento nos casos de transexualismo.

Merecem destaque os fundamentos utilizados pelo CFM para autorizar a cirurgia, relacionados à ética médica e à realização do tratamento para fins terapêuticos: ser o paciente transexual portador de desvio psicológico permanente de identidade sexual, com rejeição do fenótipo e tendência à automutilação e ou auto-extermínio; que a cirurgia de transformação plástico-reconstrutiva da genitália externa, interna e caracteres sexuais secundários não constitui crime de mutilação previsto no artigo 129 do Código Penal, visto que tem o propósito terapêutico específico de adequar a genitália ao sexo psíquico; a viabilidade técnica para as cirurgias de neocolpovulvoplastia e ou neofaloplastia. O que dispõe o artigo 199 da Constituição Federal, parágrafo quarto, que trata da remoção de órgãos, tecidos e substâncias humanas para fins de transplante, pesquisa e tratamento, bem como o fato de que a transformação da genitália constituir a etapa mais importante no tratamento de transexualismo; lembra que o artigo 42 do Código de Ética Médica ${ }^{28}$ veda os procedimentos médicos proibidos em lei, e não há lei que defina a transformação terapêutica da

\footnotetext{
${ }^{26}$ JUNGES, José Roque. Bioética: perspectivas e desafios. São Leopoldo: Ed. Unisinos, 1999, p. 47.

${ }^{28}$ Referência ao art. 42 do Código de Ética Médica então vigente, aprovado pela Resolução CFM no 1.246/88. Atualmente a disposição corresponde ao art. 14 do Código de Ética Médica, aprovado por meio da Resolução CFM no 1.931/2009, em vigor desde 13 de abril de 2010.
} 
genitália in anima nobili como crime; que o espírito de licitude ética pretendido visa fomentar o aperfeiçoamento de novas técnicas, bem como estimular a pesquisa cirúrgica de transformação da genitália e aprimorar os critérios de seleção. $^{29}$

A opção feita pelo CFM, desde esta primeira resolução sobre a matéria, deu destaque ao cuidado da saúde e da qualidade de vida dos pacientes, além de mostrar-se coerente com o princípio bioético da autonomia, como se verifica pelos requisitos elencados na resolução atualmente vigente (Resolução n 1.955/2010):

Art. $3^{\circ}$ Que a definição de transexualismo obedecerá, no mínimo, aos critérios abaixo enumerados:

1) Desconforto com o sexo anatômico natural;

2) Desejo expresso de eliminar os genitais, perder as características primárias e secundárias do próprio sexo e ganhar as do sexo oposto;

3) Permanência desses distúrbios de forma contínua e consistente por, no mínimo, dois anos;

4) Ausência de outros transtornos mentais.

A seleção dos pacientes deverá seguir as orientações definidas no art. $4^{\circ}$ que estipula a necessidade de avaliação de equipe multidisciplinar constituída por médico psiquiatra, cirurgião, endocrinologista, psicólogo e assistente social, obedecendo aos critérios a seguir definidos, após, no mínimo, dois anos de acompanhamento conjunto; diagnóstico médico de transgenitalismo; ser maior de 21 (vinte e um) anos e; ausência de características físicas inapropriadas para a cirurgia.

Além do que o tratamento do transgenitalismo deve ser realizado apenas em estabelecimentos que contemplem integralmente os pré-requisitos estabelecidos nesta resolução, bem como a equipe multidisciplinar estabelecida no art. 40; sendo o corpo clínico destes hospitais, devidamente registrado no Conselho Regional de Medicina, aos quais caberá o diagnóstico e a indicação terapêutica, e devem tais equipes ser previstas no regimento interno dos hospitais, inclusive contando com chefe, obedecendo aos critérios regimentais para a ocupação do cargo. Em qualquer ocasião, a falta de um dos membros da equipe ensejará a paralisação de permissão para a execução dos tratamentos. Além do que os hospitais deverão ter comissão ética constituída e funcionando dentro do previsto na legislação pertinente. O consentimento livre e esclarecido é condição essencial para a realização da cirurgia, conforme expressa o art. $6^{\circ}$ da resolução. ${ }^{30}$

\footnotetext{
${ }^{29}$ BRASIL. Conselho Federal de Medicina, Resolução CFM no 1.482/97. Diário Oficial da União. (Brasília), 19 set, p. 20.944, 1997.

30 BRASIL. Conselho Federal de Medicina. Resolução CFM n 1.955/2010. Diário Oficial da União. (Brasília), 03 set, seção I, p. 109-110, 2010.
} 
Diante da exigência do consentimento livre e esclarecido, bem como da análise criteriosa das características psíquicas e físicas do paciente pela equipe multidisciplinar, é possível afirmar que a finalidade única da cirurgia é o cuidado com a saúde física e psíquica do paciente, em face da irreversibilidade do procedimento. Com essas cautelas, busca-se evitar a cirurgia em pessoas cuja capacidade de decisão e avaliação possa estar alterada pela ansiedade peculiar do transtorno, ou mesmo por outros distúrbios psicológicos. Sob o prisma da Bioética, é possível afirmar que estão atendidos os princípios da autonomia e da beneficência, aqui já referidos.

Marlene Inácio e Elisa del Rosario Ugarte Verduguez destacam ainda a importância da avaliação da equipe de trabalho multidisciplinar, enfatizando que o tratamento desses pacientes é imprescindível, tanto nos aspectos técnicos de cada uma das especialidades, quanto como facilitador para apreensão dos aspectos de ordem ética e de valores que permeiam a questão do transexualismo, pois cada participante da equipe será também um fornecedor de opinião de sua classe, sendo sua responsabilidade cuidar para que o preconceito que paira sobre tais pacientes não encontre eco na equipe que os acompanha ${ }^{31}$."

Não obstante a transgenitalização seja aceita no meio médico como prática capaz de possibilitar maior qualidade de vida aos transexuais, há vozes dissonantes, como Elio Sgreccia, que não considera a cirurgia um meio legítimo de tratamento. O autor entende que a execução da intervenção médico-cirúrgica não faz, necessariamente, superar o conflito precedente; não recompõe a harmonia com o novo sexo, mas até parece agravar a sensação de frustração: passando à avaliação das consequências das intervenções, é preciso considerar, antes de mais nada, que até a mais perfeita operação não realiza nunca uma autêntica e verdadeira mudança de sexo. Acrescenta que, por meio de pesquisas realizadas, ficou claro que a intervenção cirúrgica nem sempre satisfaz às expectativas do transexual. Dificilmente se consegue a perfeita inserção do indivíduo no contexto social, sobretudo pela dificuldade que tem de resolver os problemas sexuais, uma vez que existe frequentemente a rejeição do parceiro por sua situação, elemento este que cria ulteriores frustrações. ${ }^{32}$

Contudo, o fato de ser recomendada ampla avaliação preliminar, bem como a realização de psicoterapia por no mínimo dois anos, tem justamente como propósito evitar arrependimentos e frustrações.

\footnotetext{
31 INÁCIO, Marlene; VERDUGUEZ, Elisa del Rosario Ugarte. Experiência em Avaliação Psicológica da Transexualidade no Hospital das Clínicas da Faculdade de Medicina da Universidade de São Paulo. In: VIEIRA, Tereza Rodrigues; PAIVA, Luiz Airton Saavedra de. (Org). Identidade Sexual e Transexualidade. São Paulo: Roca, 2009, p. 69.

32 SGRECCIA, Elio. Manual de Bioética. I - Fundamentos e Ética Biomédica. Trad. Orlando Soares Moreira. 2. ed., São Paulo: Edições Loyola, 2007, p. 506.
} 
Antônio Batista, sexólogo que integra o grupo da equipe multidisciplinar da Universidade de Brasília - UnB, em entrevista conferida ao programa Repórter Justiça, exibido na TV Justiça, ${ }^{33}$ alerta para que os candidatos não vivam uma fantasia: o engano de que a transformação da sexualidade seja como uma total mudança de vida. Destaca que não pode haver uma sexualização, uma genitalização da vida, nem o pensamento de que a cirurgia será a cura para todos os sofrimentos. Observa ainda que o homem que se transforma em mulher nunca será biologicamente uma mulher; será uma mulher diferenciada - terá que tomar hormônios para sempre, por exemplo.

No entanto, a cirurgia, quando realizada com a observância dos diversos critérios éticos aqui referidos, e desde que associada ao tratamento psicoterápico, é capaz de conduzir a uma melhoria significativa da qualidade de vida dos pacientes. Segundo Harold I. Kaplan, Benjamin J. Sadock, e Jack A. Grebb, "cerca de $70 \%$ dos pacientes de reatribuição sexual de homem para mulher e $80 \%$ de mulher para homem relatam resultados satisfatórios. Os resultados insatisfatórios correlacionam-se com um transtorno mental preexistente.,"34

\section{O TRATAMENTO DO TRANSTORNO DE IDENTIDADE DE GÊNERO E O DIREITO FUNDAMENTAL À SAÚDE}

A finalidade terapêutica da cirurgia de redesignação sexual fica evidenciada a partir dos fundamentos elencados pelo Conselho Federal de Medicina para autorizar aos médicos a realização de cirurgias de transgenitalização, referidos no tópico anterior. Como visto, o procedimento cirúrgico tem por escopo não apenas evitar a automutilação ou o autoextermínio, mas também minimizar o sofrimento psíquico do sujeito, proporcionando-lhe maior qualidade de vida.

A Organização Mundial da Saúde inclui o transexualismo no CID Código Internacional de Doenças (CID -10, 2000), com a seguinte definição:

(F-64.0)

Transexualismo

Um desejo de viver e de ser aceito como pessoa do sexo oposto, usualmente acompanhado por uma sensação de desconforto ou impropriedade de seu próprio sexo anatômico e um desejo de se submeter a um tratamento hormonal e cirúrgico para tornar seu corpo tão congruente quanto possível com o sexo desejado.

Assim, estando reconhecida como doença diagnosticável e tratável, e seguidos os critérios bioéticos aqui referidos, deve ser disponibilizado o

${ }^{33}$ Programa Repórter Justiça, exibido na TV Justiça em 03.09.2010.

${ }^{34}$ KAPLAN, Harold I.; SADOCK, Benjamin J.; GREBB, Jack A. Compêndio de Psiquiatria: ciências do comportamento e psiquiatria clínica. Trad. Dayse Batista. 7. ed., Porto Alegre: Artes Médicas, 1997, p. 647. 
tratamento aos transexuais, como forma de realização do direito à saúde, como referem Maria Jaqueline Coelho Pinto e Maria Alves de Toledo Bruns, os transexuais aos poucos têm sido ouvidos em suas reivindicações, para que possam ter direito à saúde, uma vez que a transexualidade diz respeito a um transtorno diagnosticável, de possível tratamento, que inclui a redesignação sexual. ${ }^{35}$

Considerando que já estão disponíveis avanços biotecnocientíficos que permitem aos transexuais alterar seu sexo físico, é possível considerar que deve haver responsabilidade do Estado em proporcionar políticas legais e de saúde em prol da redesignação sexual.

Neste sentido, Miriam Ventura observa que, a partir da possibilidade concreta de transformar o corpo, adequando-o a um sexo oposto ao sexo biológico, a transexualidade resgata e renova antigos questionamentos sobre o limite da liberdade em relação aos atos de disposição do próprio corpo, os sentidos de saúde e doença no âmbito da vivência da sexualidade, e a relevância do sexo na identificação do sujeito de direitos. O novo elemento desse debate, disparado pelos avanços biotecnocientíficos, relaciona-se à legitimidade de a pessoa alterar livremente sua identidade sexual e vivenciá-la através do uso desses novos recursos, e às responsabilidades estatais e institucionais, no sentido de garantir e promover políticas legais e de saúde que garantam o acesso às transformações. ${ }^{36}$

Alertam Ingo Wolfgang Sarlet e Mariana Filchtiner Figueiredo que a judicialização crescente das demandas no que diz respeito à concretização do direito à saúde vem cobrando cada vez mais uma ação arrojada por parte dos aplicadores do direito, em especial do Estado-Juiz, que é provocado a se manifestar sobre questões antes menos comuns, como a alocação de recursos públicos, o controle das ações da Administração na esfera dos direitos fundamentais sociais, e até mesmo a garantia da proteção de direitos e deveres fundamentais sociais na esfera das relações entre particulares. ${ }^{37}$

Como exemplo de busca de efetiva concretização e democratização do direito à saúde, convém registrar o resultado da Ação Civil Pública $n^{0}$ 2001.71.00.026279-9, movida pelo Ministério Público Federal contra a União perante a Seção Judiciária de Porto Alegre. No âmbito desta ação, o autor requeria a adoção das medidas necessárias para garantir aos transexuais

\footnotetext{
${ }^{35}$ PINTO, Maria Jaqueline Coelho; BRUNS, Maria Alves de Toledo. Avaliação Psicológica em Transexualidade no Hospital de Base de São José do Rio Preto. In: VIEIRA, Tereza Rodrigues; PAIVA, Luiz Airton Saavedra de. (Org). Identidade Sexual e Transexualidade. São Paulo: Roca, 2009 , p. 83.

${ }^{36}$ VENTURA, Miriam. Transexualidade: algumas reflexões jurídicas sobre a autonomia corporal e autodeterminação da identidade sexual. In: RIOS, Roger Raupp. (Org). Em Defesa dos Direitos Sexuais. Porto Alegre: Livraria do Advogado Editora, 2007, p. 143.

37 SARLET, Ingo Wolfgang; FIGUEIREDO, Mariana Filchtiner. Reserva do Possível, Mínimo Existencial e Direito à Saúde: algumas aproximações. In SARLET, Ingo Wolfgang; TIMM, Luciano Benetti (Org.) Direitos Fundamentais. Orçamento e "reserva do possível". Porto Alegre: Livraria do Advogado, 2010, p. 15.
} 
seu direito de ver custeadas pelo Estado as despesas médicas necessárias para sua adequação sexual.

O MPF levantou os seguintes argumentos jurídicos para postular a regulamentação, por parte do Ministério da Saúde, da remuneração de cirurgias de transgenitalização pelo SUS:

A Constituição Cidadã de 1988 consagrou o princípio de que 'a saúde é direito de todos e dever do Estado, garantido mediante políticas sociais e econômicas que visem à redução do risco de doença e de outros agravos e ao acesso universal, igualitário às ações e serviços para a sua promoção, proteção e recuperação' (art. 196 da CF/88). Este dispositivo constitucional explicita uma das facetas da dignidade da pessoa humana, que foi erigido como um dos fundamentos da República Federativa do Brasil (inciso III do art. $1^{\circ}$ da CF/88), e atende ao objetivo fundamental de "promover o bem de todos, sem preconceitos de origem, raça, sexo, cor, idade e quaisquer outras formas de discriminação" (inciso IV do art. $3^{\circ}$ da CF/88). Podemos referir, também, que o direito à saúde como expresso no art. 196 da CF/88 está em consonância com o art. $5^{\circ}$, caput, da Carta Constitucional que garante a inviolabilidade do direito à vida, à igualdade e à segurança, abrangendo esta o direito à integridade física e moral, e à saúde, sendo o direito à saúde classificado como direito social (art. 6º caput).

Além dos fundamentos constitucionais, são invocados instrumentos infraconstitucionais que sustentam o acesso a esse tratamento, a Lei $n^{\circ}$ 8.080/90, denominada de Lei Orgânica da Saúde, onde foram reguladas, em todo o território nacional, as ações e serviços de saúde, reconhecendo-se a natureza de direito fundamental do ser humano (art. $2^{\circ}$, caput), e incluindo como ações de saúde, todas aquelas medidas destinadas a garantir às pessoas e à coletividade condições de bem estar físico, mental e social (parágrafo único do art. $3^{\circ}$ ). Tal definição legal vem ao encontro da definição de saúde elaborada pela OMS e pelo UNICEF, quando da formulação da "Declaração de Alma-Ata", na República do Cazaquistão, no dia 12 de setembro de 1978: A conferência reafirma enfaticamente que a saúde estado completo de bem-estar físico, mental e social, e não simplesmente a ausência de doença ou enfermidade - é um direito humano fundamental, e que a consecução do mais alto nível possível de saúde é a mais importante meta social mundial, cuja realização requer a ação de muitos outros setores sociais e econômicos, além do setor saúde. Por fim destaca que tendo qualificado a saúde como direito de todos, de um lado, e de outro, como dever do Estado, o legislador constituinte criou o SUS - Sistema Único de Saúde, a quem incumbe a efetivação de ações e serviços públicos de saúde através de uma rede regionalizada e hierarquizada (art. 198 da CF/88). ${ }^{38}$

${ }^{38}$ Texto da petição inicial da Ação Civil Pública no 2001.71.00.026279-9 gentilmente cedido por Paulo Gilberto Cogo Leivas, Procurador Regional da República, que subscreveu a peça juntamente com Marcelo Veiga Beckhausen e Luiz Carlos Weber, também membros do MPF. 
Embora não seja um fenômeno comum - há estatísticas que indicam que a ocorrência de um caso em cada trinta mil adultos do sexo masculino (1:30.000), e de um caso para cada cem mil do sexo feminino $(1: 100.000)^{39}-$, no contingente da população brasileira o transtorno envolve um considerável número de pessoas, devendo ser tratado como uma questão de saúde pública.

A necessidade de beneficiar um elevado número de transexuais, destituídos do acesso às terapêuticas específicas, foi sublinhada pelos autores da referida ACP, em face do grande contingente de pessoas que necessitam do procedimento cirúrgico para minimizar seu sofrimento, ou ao menos 'equacioná-lo'. Ponderam ainda que, a partir da edição da Resolução CFM n ${ }^{0} 1.482 / 97$, diversos programas de atendimento aos transexuais foram instituídos em hospitais universitários ou hospitais públicos adequados à pesquisa, como é o exemplo daquele instalado junto ao Hospital de Clínicas de Porto Alegre, o Programa de Transtorno de Identidade de Gênero (PROTIG). Através do atendimento possibilitado naquela instituição, diversos candidatos ao procedimento cirúrgico já obtiveram aprovação, estando liberados e aguardando a cirurgia, após o longo período de acompanhamento indicado pela norma do Conselho Federal de Medicina. Porém, não raro as pretensões dos candidatos restam frustradas em decorrência da negativa do Ministério da Saúde em custear o procedimento. Assim, concluem os membros do MPF que, postergar essa situação vivenciada, de instabilidade emocional, "agravada pela frustração da esperança que lhes foi plantada pelos programas públicos iniciados e já em andamento, até que se obtenha o trânsito em julgado da presente demanda, não é razoável admitir-se como sendo o melhor critério de justiça." ${ }^{40}$

A sentença de primeiro grau concluiu pela procedência do pedido, tendo sido posteriormente confirmada em sede de apelação. Por sua relevância e pertinência com os aspectos aqui abordados, transcreve-se parte da ementa do acórdão, cuja relatoria coube ao Juiz Federal Roger Raupp Rios. Treze fundamentos foram destacados, a seguir:

1 - A exclusão da lista de procedimentos médicos custeados pelo Sistema Único de Saúde das cirurgias de transgenitalização e dos procedimentos complementares, em desfavor de transexuais, configura discriminação proibida constitucionalmente, além de ofender os direitos fundamentais de liberdade, livre desenvolvimento da personalidade, privacidade, proteção à dignidade humana e saúde; 2 - A proibição constitucional de discriminação por motivo de sexo protege heterossexuais, homossexuais, transexuais e travestis, sempre que a sexualidade seja o fator decisivo para a imposição de tratamentos desfavoráveis; 3 - A proibição de discriminação por motivo de sexo

${ }^{39}$ KAPLAN, Harold I.; SADOCK, Benjamin J.; GREBB, Jack A. Compêndio de Psiquiatria: ciências do comportamento e psiquiatria clínica. Trad. Dayse Batista. 7. ed., Porto Alegre: Artes Médicas, 1997, p. 643.

40 Texto da petição inicial da Ação Civil Pública nº 2001.71.00.026279-9. 
compreende, além da proteção contra tratamentos desfavoráveis fundados na distinção biológica entre homens e mulheres, proteção diante de tratamentos desfavoráveis decorrentes do gênero, relativos ao papel social, à imagem e às percepções culturais que se referem à masculinidade e à feminilidade; 4 - O princípio da igualdade impõe a adoção de mesmo tratamento aos destinatários das medidas estatais, a menos que razões suficientes exijam diversidade de tratamento, recaindo o ônus argumentativo sobre o cabimento da diferenciação. Não há justificativa para tratamento desfavorável a transexuais quanto ao custeio pelo SUS das cirurgias de neocolpovulvoplastia e neofaloplastia, pois (a) trata-se de prestações de saúde adequadas e necessárias para o tratamento médico do transexualismo e (b) não se pode justificar uma discriminação sexual (contra transexuais masculinos) com a invocação de outra discriminação sexual (contra transexuais femininos); 5 - O direito fundamental de liberdade, diretamente relacionado com os direitos fundamentais ao livre desenvolvimento da personalidade e de privacidade, concebendo os indivíduos como sujeitos de direito ao invés de objetos de regulação alheia, protege a sexualidade como esfera da vida individual livre da interferência de terceiros, afastando imposições indevidas sobre transexuais, mulheres, homossexuais e travestis; 6 - A norma de direito fundamental que consagra a proteção à dignidade humana requer a consideração do ser humano como um fim em si mesmo, ao invés de meio para a realização de fins e de valores que lhe são externos e impostos por terceiros; são inconstitucionais, portanto, visões de mundo heterônomas, que imponham aos transexuais limites e restrições indevidas, com repercussão no acesso a procedimentos médicos; 7 - A força normativa da Constituição, enquanto princípio de interpretação, requer que a concretização dos direitos fundamentais empreste a maior força normativa possível a todos os direitos simultaneamente, pelo que a compreensão do direito à saúde deve ser informada pelo conteúdo dos diversos direitos fundamentais relevantes para o caso; 8 - O direito à saúde é direito fundamental, dotado de eficácia e aplicabilidade imediatas, apto a produzir direitos e deveres nas relações dos poderes públicos entre si e diante dos cidadãos, superada a noção de norma meramente programática, sob pena de esvaziamento do caráter normativo da Constituição; 9 - A doutrina e a jurisprudência constitucionais contemporâneas admitem a eficácia direta da norma constitucional que assegura o direito à saúde, ao menos quando as prestações são de grande importância para seus titulares e inexiste risco de dano financeiro grave, o que inclui o direito à assistência médica vital, que prevalece, em princípio, inclusive quando ponderado em face de outros princípios e bens jurídicos; 10 - A inclusão dos procedimentos médicos relativos ao transexualismo, dentre aqueles previstos na Tabela SIH-SUS, configura correção judicial diante de discriminação lesiva aos direitos fundamentais de transexuais, uma vez que tais prestações já estão contempladas pelo sistema público de saúde; 11- Hipótese que configura proteção de direito fundamental à saúde derivado, uma vez que a atuação judicial elimina discriminação indevida que impede o acesso igualitário ao serviço público; 
12 - As cirurgias de transgenitalização não configuram ilícito penal, cuidando-se de típicas prestações de saúde, sem caráter mutilador. 13 - As cirurgias de transgenitalização recomendadas para o tratamento do transexualismo não são procedimentos de caráter experimental, conforme atestam Comitês de Ética em Pesquisa Médica e manifestam Resoluções do Conselho Federal de Medicina. ${ }^{41}$

Após a decisão, proferida em agosto de 2007, o Ministério da Saúde regulamentou os procedimentos para a realização da cirurgia pelo Sistema Único de Saúde, por meio da Portaria n 457/2008.

Cabe ainda destacar que, não obstante a democratização da cirurgia represente um grande avanço, ainda resta pendente a normatização da alteração do prenome e do sexo no registro de nascimento e demais documentos de identificação dos transexuais. Sobre os transtornos vivenciados pelos indivíduos nessa condição, Miriam Ventura destaca que além das transformações corporais, a pessoa transexual busca alterar seu prenome e sexo legal. Esta mudança de elementos do estado da pessoa é considerada como fundamental para o pleno sucesso da terapia de 'mudança de sexo', vez que permite cessar os constrangimentos pessoais e sociais de se viver um sexo oposto a de sua identificação civil, favorecendo o livre desenvolvimento da personalidade e integração social da pessoa submetida às transformações. ${ }^{42}$

Para Tereza Rodrigues Vieira, o direito deve andar de mãos dadas com o bom senso, assegurando a veracidade dos fatos, a liberdade de cada um sobre seu próprio corpo deve curvar-se diante das legítimas necessidades da vida social e da ciência, sobretudo nos casos onde se objetiva o restabelecimento da saúde. Assim, destaca a autora que o direito à adequação do sexo do transexual está amparado na Lei dos Registros Públicos, Lei 6.015/73, modificada pela Lei 9.708/98, bem como nos arts. $3^{\circ}$, IV , 5, X, 196, 199 da Constituição Federal, e na Lei de Introdução ao Código Civil, no direito à vida privada, direito à saúde, direito à identidade pessoal e no art. $2^{\circ}$ da Declaração Universal do Genoma Humano e dos Direitos Humanos, de 1997, que estabelece que todos têm direito ao respeito por sua dignidade e seus direitos humanos, independentemente de suas características genéticas. Assim, todos os indivíduos não podem ser reduzidos à suas características genéticas, mas devem ser respeitados em sua singularidade e diversidade. ${ }^{43}$

\footnotetext{
${ }^{41}$ Tribunal Regional Federal da 4a Região, Apelação Cível n 2001.71.00.026279-9, Terceira Turma, Relator Roger Raupp Rios, D.E. 22.08.2007.

${ }^{42}$ VENTURA, Miriam. Transexualidade: algumas reflexões jurídicas sobre a autonomia corporal e autodeterminação da identidade sexual. In: RIOS, Roger Raupp. (Org). Em Defesa dos Direitos Sexuais. Porto Alegre: Livraria do Advogado Editora, 2007, p. 142.

${ }^{43}$ VIEIRA, Tereza Rodrigues. Nome e Sexo: mudanças no registro civil. São Paulo: RT, 2008, p. 223.
} 
Pelo fato de ainda inexistir regulamentação sobre os efeitos jurídicos da cirurgia de transexualização, muitos transexuais têm recorrido ao Poder Judiciário para que o reconhecimento de seu direito à alteração de seu prenome e sexo no registro civil.

$\mathrm{O}$ direito à identidade pessoal compreende primeiramente o direito ao nome (prenome e sobrenome), mas também íntima ligação com o direito à própria imagem e à intimidade. Há que se considerar que dentre as características fundamentais das sociedades contemporâneas está na importância do cidadão, de sua auto-identidade e da expressão da diversidade sexual. ${ }^{44}$ Essa nova identidade deve ser concedida tanto ao transexual que se submeteu à cirurgia de redesignação sexual quanto àquele que não a fez, na medida em que o sexo social deve preponderar sobre o sexo biológico.

Cabe citar que ainda pende de análise pelo Poder Legislativo o Projeto de Lei n ${ }^{\circ} 6.655 / 06$, encaminhado pelo Deputado Luciano Zica, objetivando a alteração do art. 58 da Lei n 6.015/73 - Lei de Registros Públicos, a fim de possibilitar a substituição do prenome de pessoas transexuais. Segundo o projeto, em que pese permanecer a determinação de que o prenome será definitivo, seria admitida sua substituição quando o interessado fosse reconhecido como transexual, de acordo com laudo de avaliação médica, e independentemente da prévia realização do procedimento médico-cirúrgico destinado à adequação dos órgãos sexuais.

\section{CONSIDERAÇÕES FINAIS}

A partir da necessidade de readequação sexual - entendido o problema vivenciado pelas pessoas transexuais como um transtorno causador de relevante sofrimento psíquico -, foi possível garantir o acesso à terapêutica adequada, culminando com a oferta, por meio do Sistema Único de Saúde, da cirurgia de transgenitalização.

Obviamente, a questão da redesignação sexual suscita diversas questões no plano jurídico, tais como a alteração do prenome e sexo com ou sem a realização de cirurgia, além de outros desdobramentos relativos ao gênero, tal como o casamento, que até o momento só é admitido entre pessoas de sexos diferentes.

No entanto, objetivou-se nesse estudo abordar certos aspectos debatidos no campo da Bioética acerca da cirurgia de transgenitalização. Analisados os preceitos ditados pela prática médica, é possível afirmar que no Brasil a regulamentação deste procedimento cirúrgico almejou que fossem observados aspectos éticos importantes, salvaguardando a autonomia do paciente e buscando unicamente a melhoria de sua saúde e de sua qualidade de vida.

44 BRAUNER, Maria Cláudia Crespo; MOURA, Oyára Cristina Costa de. Transexualidade: a redefinição da sexualidade e o direito à identidade pessoal. In: Direito e Cidadania. In: LOBATO, Anderson Orestes Cavalcante; LONDERO, Josirene Cândido; DANTAS, Roberto Ribeiro Dantas (Org.). Juiz de Fora: Editar, 2006, p. 77. 
Desta forma, diante do sofrimento psíquico gerado pelo permanente sentimento de inadequação de seu corpo ao seu sexo psíquico, fica explícita a necessidade de proporcionar tratamento médico adequado aos transexuais, observados os parâmetros fornecidos pela Bioética, como uma questão de respeito aos Direitos Humanos, e notadamente como realização do direito à saúde.

\section{REFERÊNCIAS BIBLIOGRÁFICAS}

ASSOCIAÇÃO AMERICANA DE PSIQUIATRIA. Manual Diagnóstico e Estatístico de Transtornos Mentais - DSM-IV. Trad. Cláudia Dornelles. 4. ed., Porto Alegre: Artmed, 2002.

BRASIL. Constituição da República Federativa do Brasil 1988. Porto Alegre: Verbo Jurídico, 2004

. Conselho Federal de Medicina, Resolução CFM no 1.482/97. Diário Oficial da União. (Brasília), 19 set, p. 20.944, 1997.

Conselho Federal de Medicina. Resolução CFM n 1.652/2002. Diário Oficial da União. (Brasília), 02 dez, seção I, p. 80, 2002.

Conselho Federal de Medicina. Resolução CFM n 1.955/2010. Diário Oficial da União. (Brasília), 03 set, Seção I, p. 109-110, 2010.

BRAUNER, Maria Cláudia Crespo; MOURA, Oyára Cristina Costa de. Transexualidade: a redefinição da sexualidade e o direito à identidade pessoal. In: Direito e Cidadania. LOBATO, Anderson Orestes Cavalcante; LONDERO, Josirene Cândido; DANTAS, Roberto Ribeiro (Org.). Juiz de Fora: Editar, 2006, p. 73-84.

CHAVES, Antônio. Direito à Vida e ao próprio corpo. São Paulo: Editora Revista dos Tribunais, 1995.

FABRIZ, Daury Cesar. Bioética e Direitos Fundamentais: a bioconstituição como paradigma ao biodireito. Belo Horizonte: Mandamentos, 2003.

FOUCAULT, Michel. História da Sexualidade I: A vontade de saber. Trad. Maria Thereza da Costa Albuquerque e J. A. Gilhon de Albuquerque. Rio de Janeiro: Edições Graal, 1988.

JUNGES, José Roque. Bioética: perspectivas e desafios. São Leopoldo: Ed. Unisinos, 1999.

KAPLAN, Harold I.; SADOCK, Benjamin J.; GREBB, Jack A. Compêndio de Psiquiatria: ciências do comportamento e psiquiatria clínica. Trad. Dayse Batista. 7. ed., Porto Alegre: Artes Médicas, 1997.

LYPOVETSKI, Gilles. O Crepúsculo do Dever. A ética indolor dos novos tempos democráticos. Trad. Fátima Gaspar e Carlos Gaspar. Lisboa: Dom Quixote, 2004.

MOURA, Oyára Cristina Costa de. Transexualidade: a reconstrução jurídica da identidade sexual do indivíduo à luz dos direitos da personalidade. Dissertação (Mestrado em Direito). Programa de Pós-graduação em Direito, Universidade de Caxias do Sul, Caxias do Sul, RS, 2004.

PESSINI, Leo; BARCHIFONTAINE, Christian de Paul de. Problemas atuais de Bioética. 8. ed., São Paulo: Edições Loyola, 2007.

PINTO, Graziela Costa (Org.). Uma Questão de Gênero. São Paulo: Duetto Editorial, 2008. (Sexos, a trama da vida; 3). 
RAMSEY, Gerald. Transexuais: perguntas e respostas. Trad. Rafael Azize. São Paulo: Summus, 1998.

RIOS, Roger Raupp. (Org). Em Defesa dos Direitos Sexuais. Porto Alegre: Livraria do Advogado Editora, 2007.

RITO, Lucia. Muito Prazer, Roberta Close. Rio de Janeiro: Record, 1998.

SARLET, Ingo Wolfgang; FIGUEIREDO, Mariana Filchtiner. Reserva do Possível, Mínimo Existencial e Direito à Saúde: algumas aproximações. In SARLET, Ingo Wolfgang; TIMM, Luciano Benetti (Org.) Direitos Fundamentais. Orçamento e "reserva do possível". Porto Alegre: Livraria do Advogado, 2010. p. 13-50.

SGRECCIA, Elio. Manual de Bioética. I - Fundamentos e Ética Biomédica. Trad. Orlando Soares Moreira. 2. ed., São Paulo: Edições Loyola, 2007.

VIEIRA, Tereza Rodrigues; PAIVA, Luiz Airton Saavedra de. (Org). Identidade Sexual e Transexualidade. São Paulo: Roca, 2009.

Nome e Sexo: mudanças no registro civil. São Paulo: RT. 2008. 